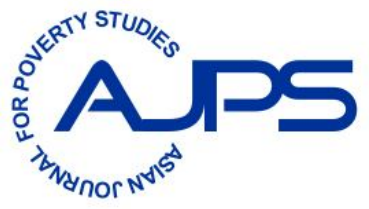

ISSN 2477-0531

\title{
THE APPLICATION OF PARTICIPATORY PROSPECTIVE ANALYSES TO DEVISE WOMEN EMPOWERMENT PROGRAMS FOR REDUCING POVERTY: CASE STUDY IN SOUTH BENGKULU REGENCY, BENGKULU PROVINCE, INDONESIA
}

\author{
Agustina Erni ${ }^{1}$, Pribudiarta N. Sitepu ${ }^{1}$, Indra Gunawan ${ }^{1}$, \\ Teguh Adiprasetyo ${ }^{2 *}$, Rohidin Mersyah ${ }^{3}$ \\ ${ }^{1}$ Ministry of Women Empowerment and Child Protection, Jl. Merdeka Barat 15, Jakarta, Indonesia \\ ${ }^{2}$ Faculty of Agriculture, University of Bengkulu, Jl. WR Supratman, Bengkulu, Indonesia \\ ${ }^{3}$ South Bengkulu Regency, Jl. Raya Padang Panjang No.1, Manna, Bengkulu Selatan, Indonesia
}

Corresponding Author: teguhadi@yahoo.com

\begin{abstract}
This study is intended to apply participatory prospective analysis to formulate women empowerment programs and activities to reduce poverty. Participatory prospective analysis may facilitate the process of integrating multiple stakeholders' preferences in public policy decision since the involvement of stakeholders as part of the poverty alleviation solution; it can be expected to increase the effectiveness of the programs and activities. This study was conducted in South Bengkulu Regency, Bengkulu Province, Indonesia. Data were collected through focus group discussion (FGD). A number of 23 participants from various delegates of stakeholders including head or officers of regency government and its regional working units, non government organizations, community groups and local university were involved in the FGD. Data were analysed using participatory prospective method. The results reveal that there are 15 factors identified shaping the system of women empowerment for poverty reduction. By using a fourquadrant window, those factors are grouping into four categories: input, stakes, unused, and output, as the key of the empowered programs. Input factors are human resource skills, social cultural, formal education attainment and health status. The stakes are access to natural resources, access to capital, local policies and access to decision making process. While the unused factors are past experiences, infrastructure and technology. The outputs are employment, community empowerment, motivation, and job availability. This study shows that the strategy to reduce poverty have to be done via women empowerment programs, which are comprising better off education, skill development, health status and social culture. Access to education, skills and health should be part of the poor asset. Poor women need to equip with assets to reduce their vulnerabilities.
\end{abstract}

Key words: women empowerment, poverty reduction, participatory, prospective analysis

\section{INTRODUCTION}

The global commitment to poverty reduction was clearly articulated through the Millenium Development Goals that set specific targets and indicators of success. However, responsibility for achieving the goal of cutting global poverty rate lies firmly at the hand of domestic governments (Besley \& Burgess, 2003). In Indonesia, poverty reduction has also become a major policy initiative. The government has established for instance the social safety net covering food security, health, education, employment creation and community empowerment. At this time, poverty reduction initiatives can be grouped into social assistance to ease burdens of the poor to fulfill the basic needs, community empowerment to improve basic social and economic services, and microenterprise empowerment to provide better working financial access (Suryahadi et al., 2010).

Poverty was used to be measured based solely on consumption or income level under the traditional economics-based approach. Recently, the definition of poverty had been broadened to reflect concerns in various aspects and characteristics of the lives of the poor. A greater attention had been put on the delivery of social services, such as education and health care to better reflect the quality of life which can not be 


\section{The application of participatory prospective analyses}

revealed by consumption and income level. Then, the meaning of poverty was further extended to include the vulnerability of the poor and understanding the lives of the poor in the context of their social and political relationships. Broadening the definition of poverty has made an important contribution toward developing multidimensional approaches to poverty reduction corresponding to the overall picture of the lives of the poor as opposed to the single indicator-based poverty line approach. The multi-dimensional nature of poverty and the multi-dimensional approaches to poverty reduction should also respond to the most urgent concerns of the poor (Yanagihara, 2003; Lustig \& Stern, 2000). Since poverty is multidimensional, poor people need a range of assets and capabilities at the individual level and at the collective level, such as the ability to organize and mobilize to take collective action to solve their problems (Narayan, 2002).

Decentralisation and regional autonomy in Indonesia create Provincial and Regency governments to have the authority and right to enact policies and programs more autonomously including poverty alleviation policy and program. At the same time, these local governments are also now demanded to be more responsive to local issues and needs (Andrianto, 2006). Local governments are expected to understand the needs and capabilities of their community better than the central government (Miranti et al., 2013). This opportunity implies that the local governments may involve poor communities and other stakeholders to participate in the development of poverty alleviation policies and programs. The involvement of stakeholders as part of the poverty alleviation solution can be expected to increase the effectiveness of the programs and activities. Khan (2013) indicates that decentralization leaded to improvements in economic growth which may in turn reduce poverty and advancement provision of public services, and increase participation and empowerment. However, in order to alleviate poverty effectively by using multi-dimensional approach, central and local governments should lead and coordinate poverty alleviation programs so that the objectives of the programs can be achieved effectively (Swastika and Supriyatna, 2008).

Gender-based disparities are bad for growth, wealth creation and poverty reduction. Gender inequality not only erodes human security, but also deepens vulnerabilities and exclusion in society. Inequalities in access to and benefits from resources, capacities and potentials reinforce the systemic barriers to a more equitable distribution of opportunities in education, income, health and wider life chances in society (Francisco, 2007). Gender disparities relate to and link with poverty reduction, economic growth and wellbeing. Gender disparities disadvantage women and girls and limit their capacity to participate in development and poverty reduction initiatives (Mumtaz, 2007). Poverty is gendered in its predisposing factors, in its processes and in its impact. Women are more likely than men to live in poverty (Budlender, 2005). Therefore, integrating gender equality, equity and women empowerment in poverty reduction programs is necessary in any poverty reduction endeavor to success. In other word, improving gender equality, equity and women empowerment may reduce poverty (Awumbila, 2006).

Participatory prospective analysis method according to Bourgeois and Jesus (2004) is progressively becoming essential technique for policy decisions, especially for strengthening the capacity of stakeholders to become more active in making decisions related to their own future. The use of participatory prospective analysis also offers regency stakeholders an opportunity to comprehend gender equality, women empowerment and systemic-multidimensional issues of poverty. Hopefully, they may adopt the method, initiate and implement women empowerment scenario and activities for poverty reduction that are acceptable and meaningful to the poor. Accordingly, the study is intended to apply participatory prospective analysis to develop women empowerment scenario for reducing poverty.

\section{RESEARCH METHOD}

This study was conducted in South Bengkulu Regency, Bengkulu Province, Indonesia. The case study of the application of participatory prospective analyses was the South Bengkulu Regency Government. Data were collected through focus group discussion (FGD). Focus group discussion comprised of 23 people of stakeholders who were responsible or impacted by women empowerment programs and activities in South Bengkulu Regency. The stakeholders involved in FGD consisted of Vice Regent, Head of Regional Development Planning Board, Head or officers of Regional Working Units related to women empowerment program and activities, such as Agency for Women Empowerment, Agency for Community Empowerment, Department of Education, Department of Health and Department of Agriculture of South Bengkulu Regency, representative of non government organizations, community groups and local university. 
Data were analysed using participatory prospective which was designed to facilitate the process of integrating multiple stakeholders' preferences in public policy decision method (Jesus and Bourgeois, 2003; Bourgeois and Jesus, 2004). The steps of participatory prospective method were:

1. Defining of the issue or purpose of the system studied. The issue could be regarded as a system that can be partitioned into factors. The participants of FGD were asked grasping well the scope and the nature of the system studied.

2. Identifying of emerging factors that might have an influence on the evolution of the system. The objective of this step is to establish a list of factors enabling participants of FGD to understand better the system studied. In order to ensure equal participation among the participants of FGD, the process of factor identification is based on the free expression of individual opinion. After having lists of factors, the next step is to discuss the relevance of these factors and select the key factors.

3. The last step, to analyze mutual influence of factors. Participants of FGD were requested to examine the direct influence of each factors on the others. The examination was based on the assessment value scale of 0 to 3 as shown in Table 1 . The data entry process was carried out directly for each factor only after it was agreed by all participants. Interpreting of the graph and the type of the factors. The influencedependence graph, as shown in Figure 1 displayed how the factors were scattered in a four-quadrant space delimited by two axes. The graph was based on the weighted influence-dependence value of each factor calculated from the influence score of each factor on the others. Interpretation of results was the position of the factors in the quadrant space and the characteristics of factors. Each quadrant in the graph corresponded to specific characteristics of the factors. The upper-left quadrant was the area of the input factors) where most influent and independent factors were present. The upper-right quadrant matched with linkage factors (stake factors). Factors in this quadrant had strong influence and dependence to the system. The lower-right quadrant corresponded to the output factors. Key factors were strong dependence and little influence factors. Autonomous factors (unused) are little influent and little dependent factors found in the lower-left quadrant.

4. Formulating programs and activities of women empowerment for poverty reduction was constructed based on dependent factors and/or linkage factors.

Table 1. Assessment value of influence between factors

\begin{tabular}{cl}
\hline Score & Description \\
\hline 0 & No influence between factors \\
1 & Small influence \\
2 & Medium influence \\
3 & Strong influence \\
\hline
\end{tabular}

Source: Bourgeois and Jesus (2004)

\section{RESULTS AND DISCUSSION}

The issue defined in the preliminary discussion among stakeholders was how to develop women empowerment programs and activities for poverty reduction in South Bengkulu Regency Government effectively. According to Bourgeois and Jesus (2004) the issue can be regarded as a system whose nature or factors can be characterized or broken down into elements. Following to the definition of the system, participants of FGD had identified factors influencing the system and analyzed mutual influence of the factors. Result of factor identification and mutual influence analysis is presented in Table 2 and Figure 2. Based on the analysis results, factors formal education attainment, human resource skills, health status and social cultural are most influent and independent. This suggests that programs that will be developed should be in the area of these factors if the effectiveness of the programs is expected.

Programs to improve women empowerment through education and skill development should be prioritized since the programs could be expected to reduce poverty. Education is one of the assets of the poor. Faced with harsh realities, many poor parents can not afford to send their children to school or keep them in school. Poor people want to educate their children but calculate that the returns to their investment 
Table 2. Characteristics of factors

\begin{tabular}{lllll}
\hline No & Factor & Influence & Dependence & Type of factor \\
\hline 1 & Job availability & 0.74 & 1.08 & Dependent \\
2 & Human resource skills & 1.27 & 0.99 & Independent \\
3 & Access to natural resources & 1.11 & 1.15 & Linkage \\
4 & Access to capital & 1.07 & 1.13 & Linkage \\
5 & Technology & 0.84 & 0.58 & Autonomous \\
6 & Social cultural & 1.03 & 0.99 & Independent \\
7 & Local policies & 1.27 & 1.20 & Linkage \\
8 & Infrastructures availability & 0.89 & 0.68 & Autonomous \\
9 & Formal education attainment & 1.25 & 0.95 & Independent \\
10 & Health status & 1.06 & 0.97 & Independent \\
11 & Motivation & 0.76 & 1.35 & Dependent \\
12 & Community empowerment & 0.79 & 1.11 & Dependent \\
13 & Access to decision making process & 1.08 & 1.09 & Linkage \\
14 & Past experiences & 0.87 & 0.42 & Autonomous \\
15 & Employment & 0.98 & 1.31 & Dependent \\
\hline
\end{tabular}

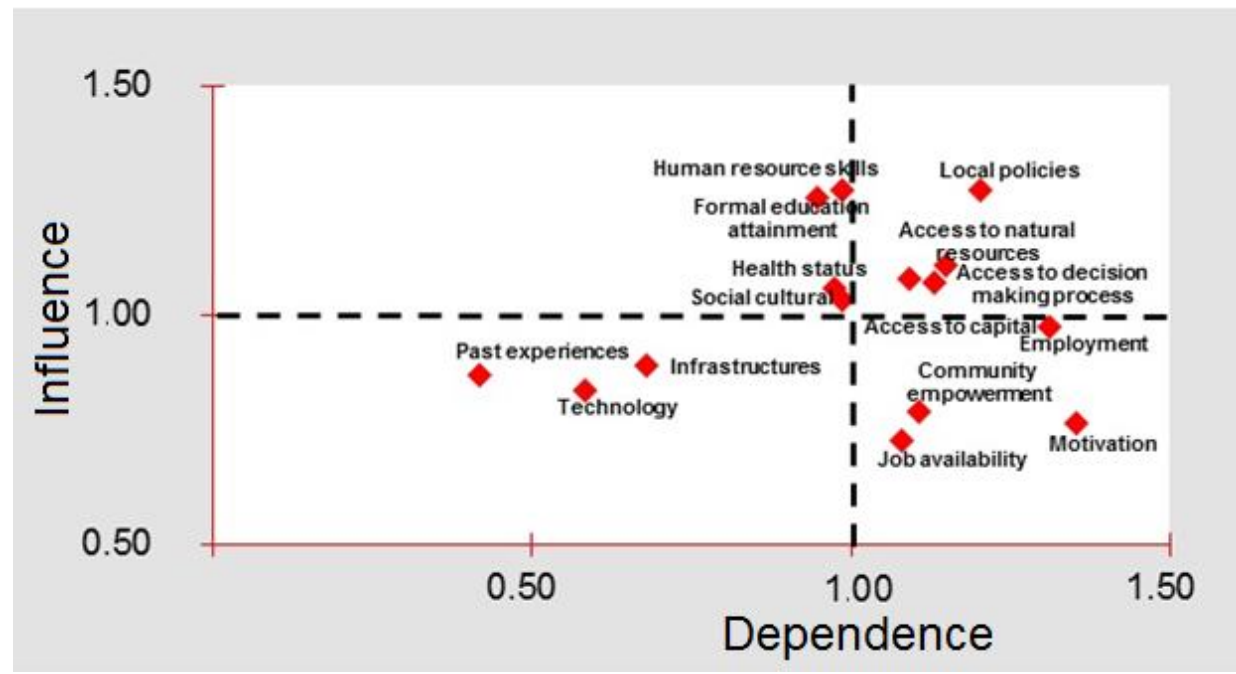

Figure 2. The importance's level of factors influencing the system

are not rewarding (Narayan, 2000). Therefore, government should intervene into this area. Based on Rahman (2013) findings, the incidence of poverty is high in households with young household heads, low-level education of the household heads, disability of household members and female-headed households. Moorosi (2009) also mentioned that education and skills development had been placed at the center of development and economic growth in South Africa, however this approach without addressing gender equality run the risk of perpetuating poverty and economic inequalities between men and women. Programs and activities should facilitate and boost education attainment for girls and boys and skills of women and men since these will increase their capabilities and self-confidence. Increasing capabilities and selfconfidence then will unlock better access to resources and motivate them to utilize available opportunities and jobs.

Women empowerment should be an essential element in these programs and activities that seek to address poverty since there is significant differences in earnings, educational levels, life expectancy, and 
unemployment rates between men and women in South Bengkulu Regency, as shown by Gender Development Index of 71.08 and Gender Empowerment Index of 61.45 (MWECP, 2012). The women access to and use of technology were low since the skills of women were not conducive to utilize technology. Consequently, the benefits of technology for women were also insignificant. Therefore, the scenario proposed for enhancing women skills is raising the mastery of appropriate-simple technology for women to deliver added value to the production of rural community and increase businesses and employment. The skills and ability of women in mastery appropriate technology will also increase the potential processing of natural resources available locally. In addition, the necessity of women mastery of appropriate technology needs to be supported by thoughtfulness of husbands, religious and community leaders. Therefore, programs, such as training for enhancing partnership need to be developed.

Other programs were to improve health status and social culture. Protecting the health of the poor means retaining asset of the poor since body is often the only asset of the poor. Poor people need assets to reduce their vulnerability and powerlessness. Poor people need access and affordable health care, water, sanitation and energy-saving services in order to maintain their health (Narayan, 2000). Social culture, especially social capital promotes a conducive environment for development and solidariry that are resulted from social cohesion, common identification with certain form of governance, cultural expression and social behaviour that make society be more cohesive and more than a sum of individuals (Baas and Rouse, 1997). The development of social empathy is a new way to approach amelioration of the economic disparity, inequality of opportunity, and social distance between the haves and the poor. When social empathy have been developed, people are more likely to develop practices, services, programs and policies that promote social justice and better response to the needs of the poor (Segal, 2007). Therefore, social culture that promotes gender equality and women empowerment were believed to enhance the effectiveness of poverty reduction programs.

The proposed programs and activities of women empowerment for reducing poverty which came up from FGD are finally for income generating activities, establishing group supporters, training and enhancing partnership. Group-based approach income generating activities should be organized by locally established samall group using locally available human resource skills. Group-based approach will generate effective collective learning, increasing problem capacities, and improving enterprise management skills (Baas and Rouse, 1997). Once this improvement materialized, social capital will develop and in turn it will affect community empowerment and employment and also create motivation and job availability.

\section{CONCLUSION}

In the development of women empowerment programs and activities for poverty reduction in South Bengkulu Regency Government effectively, factors most influent and independent are formal education attainment, human resource skills, health status and social cultural. Women empowerment programs that will be developed should be in the area of these factors if the effectiveness of the programs is expected. Programs to improve women empowerment through education and skill development should be prioritized since the programs could be expected to reduce poverty. Education is one of the assets of the poor. Increasing education attainment and skills of women as to enhance gender equality can be expected to reduce poverty since there are still significant differences in earnings, educational levels, life expectancy, and unemployment rates between men and women in South Bengkulu Regency. Other programs were to improve health status and social culture. Protecting the health of the poor means retaining asset of the poor since body is often the only asset of the poor. Poor people need assets to reduce their vulnerability and powerlessness. Social culture that promotes gender equality and women empowerment were believed to enhance the effectiveness of poverty reduction programs.

\section{REFERENCES}

Andrianto, A. 2006. The Role of district government in poverty alleviation: Case studies in Malinau and West Kutai Districts, East Kalimantan, Indonesia. Bogor: Center for International Forestry Research.

Awumbila, M. 2006. Gender equality and poverty in Ghana: implications for poverty reduction strategies. GeoJournal 67: 149-161. 


\section{The application of participatory prospective analyses}

Baas, S. and J. Rouse. 1997. Poverty alleviation: the role of rural institutions and participation. In de Anda, G.G., J. Riddell, J.Dey-Abbas, J. Rouse, S. Baas, E. Chengu (Eds). Land Reform, Land Settlement and Cooperative. Rural Development Division, FAO. Rome, Italy.

Besley, T. and R. Burgess. 2003. Halving global poverty. The Journal of Economic Perspectives 17 (3): 3-22.

Bourgeois, R. and F. Jesus. 2004. Participatory prospective analysis: Exploring and anticipating challenges with stakeholders. CAPSA Monograph No.46, United Nation.

Budlender, D. 2005. Women and poverty. Agenda 19(64): 30-36.

Francisco, J.S. 2007. Gender inequality, poverty and human development in South East Asia. Development 50 (2): 103-114.

Jesus, F. and Bourgeois, R. (2003). Reconciling Actors' Preferences in Agricultural Policy - Towards a New Management of Public Decisions. CGPRT Center Monograph No.44, United Nation.

Khan, S.A. (2013). Decentralization and poverty reduction: a theoritical framework for exploring the linkage. International Review of Public Administration 18 (2): 145-172.

Lustig, N. and N. Stern. 2000. Broadening the agenda for poverty reduction: opportunity, empowerment, security. Finance and Development 37 (4): 3-7.

MWECP [Ministry of Women Empowerment and Child Protection]. 2012. Gender based development 2012. Jakarta: Ministry of Women Empowerment and Child Protection, and Statistics Indonesia.

Miranti, R., Y. Vidyattama,, E. Hansnata, R. Cassells, and A. Duncan. 2013. Trends in poverty and equality in desentralising Indonesia. OECD Social, Employment and Migration Working Paper No.148. OECD Publishing.

Moorosi, P. 2009. Gender, skills development and poverty reduction. Agenda 23(81):110-117.

Mumtaz, K. 2007. Gender and poverty in Pakistan. Development 50(2): 149-153.

Narayan, D. 2000. Poverty is powerlessness and voicelessness. Finance and Development 37(4): 17-21.

Narayan, D. 2002. Empowerment and poverty reduction - a sourcebook. The World Bank, Washington D.C

Rahman, M.A. 2013. Household characteristics and poverty: a logistic regression analysis. The Journal of Developing Areas 47 (1): 303-317.

Segal, E.A. 2007. Social empathy: a new paradigm to address poverty. Journal of Poverty 11(3): 65-81.

Suryahadi, A., A. Yumna, U.R. Raya, and D. Marbun. 2010. Review of government's poverty reduction strategies, policies and programs in Indonesia. Jakarta: The SMERU Research Institute.

Swastika, D.K.S. and Y. Supriyatna. 2008. The characteristics of poverty and its alleviation in Indonesia. Forum Penelitian Agro Ekonomi 26 (2): 103-115.

Yanagihara, T. 2003. Approach to poverty reduction in developing countries and Japan's contribution. Technology and Development 16: 10-14. 